\title{
Long non-coding RNAs are novel players in oral inflammatory disorders, potentially premalignant oral epithelial lesions and oral squamous cell carcinoma (Review)
}

\author{
KAIYING ZHANG, WEI QIU, BULING WU and FUCHUN FANG \\ Department of Stomatology, Nanfang Hospital, Southern Medical University, Guangzhou, Guangdong 510515, P.R. China
}

Received February 13, 2020; Accepted May 15, 2020

DOI: $10.3892 /$ ijmm.2020.4628

\begin{abstract}
In recent years, a large number of studies have shown that the abnormal expression of long non-coding (lnc)RNAs can lead to a variety of different diseases, including inflammatory disorders, cardiovascular disease, nervous system diseases, and cancers. Recent research has demonstrated the biological characteristics of lncRNAs and the important functions of lncRNAs in oral inflammation, precancerous lesions and cancers. The present review aims to explore and discuss the potential roles of candidate lncRNAs in oral diseases by summarizing multiple lncRNA profiles in diseased and healthy oral tissues to determine the altered lncRNA signatures. In addition, to highlight the exact regulatory mechanism of lncRNAs in oral inflammatory disorders, potentially premalignant oral epithelial lesions and oral squamous cell carcinoma. The detection of lncRNAs in oral samples has the potential to be used as a diagnostic and an early detection tool for oral diseases. Furthermore, lncRNAs are promising future therapeutic targets in oral diseases, and research in this field may expand in the future.
\end{abstract}

\section{Contents}

1. Introduction

2. LncRNA biogenesis

3. Role of lncRNAs in oral inflammatory disorders

4. Role of lncRNAs in PPOELs

5. Role of lncRNAs in OSCC

6. Conclusions

Correspondence to: Professor Fuchun Fang or Professor Buling Wu, Department of Stomatology, Nanfang Hospital, Southern Medical University, 1838 Guangzhou Northern Road, Guangzhou, Guangdong 510515, P.R. China

E-mail: fangfuchun520@163.com

E-mail: bulingwu@smu.edu.cn

Key words: long non-coding RNA, oral inflammatory disorders, oral squamous cell carcinoma, potentially premalignant oral epithelial lesions, oral disease

\section{Introduction}

Oral inflammatory disorder is a series of processes associated with microbial infections (such as periodontal, endodontic and periapical diseases) and immune-mediated damage [for example Sjögren's syndrome (SS)] (1). Numerous factors, including non-coding (nc)RNAs, leukocytes, cytokines and complement components, are involved in this process $(2,3)$. Long non-coding (lnc)RNAs affect oral inflammation by sponging microRNAs (miRNA/miR) (4) or activating downstream target miRNAs (5). Research on competing endogenous (ce)RNA mechanisms, in which lncRNAs sponge specific miRNAs to suppress their target genes, has increased in numbers in over the last 2 years (6). For example, lncRNA metastasis associated lung adenocarcinoma transcript 1 (MALAT1) acts as a sponge of miR-20a to induce Toll-like receptor 4 (TLR4) signaling and results in an inflammatory reaction from human gingival fibroblasts (HGFs) (7).

Several potentially premalignant oral epithelial lesions (PPOELs) are associated with the disease process of chronic inflammatory disorders $(8,9)$. PPOEL is a broad term to define both histological and clinical oral lesions that have malignant potential, including oral lichen planus (OLP), oral submucous fibrosis (OSF), and oral dysplasia (10). In addition, other vital epigenetic and subcellular regulatory non-coding transcripts, such as IncRNAs and miRNAs are also known to regulate the mRNA expression of inflammation-related cytokines, and disturbance of the miRNA-mRNA-cytokine regulatory network is one of the common pathological features of PPOELs $(11,12)$. For example, the significant upregulation of miR-31 and downregulation of its target gene, C-X-C motif chemokine ligand 12 (CXCL12) contributed to progression of PPOELs (13).

As the 7th hallmark of cancer, chronic inflammation has been linked to various stages of tumorigenesis (14). Several studies have reported that numerous regulators, including inflammatory cytokines and ncRNAs, facilitate tumor development $(15,16)$. LncRNAs participate in the transformation of chronic inflammation into cancer by altering the expression of various inflammatory signaling pathways such as NF- $\mathrm{\kappa B}$ and STAT3 and proinflammatory cytokines [such as tumor necrosis factor (TNF) family]. Interleukin (IL)-6-dependent STAT3 signaling activation contributes to the occurrence of colorectal cancer (17). The major histological type of oral cancer is oral 
squamous cell carcinoma (OSCC) (18). Jia et al (19), identified that differentially expressed (DE) IncRNAs and genes between OSCC, oral dysplasia, and normal oral tissues may control the initiation and development of OSCC through phosphatidylinositol-3-kinases (PI3K)/Akt signaling and mast cell NF- $\kappa \mathrm{B}$ functional pathways.

LncRNAs play an essential role in the occurrence and development of inflammation and cancer $(20,21)$. The oral diseases associated with the function of IncRNAs are shown in Fig. 1. According to previous reports, the DE IncRNAs between healthy and pathological oral tissues may affect the occurrence and process of oral diseases (Table I). The present review outlines the current understanding of the established functions and underlying mechanisms of lncRNAs in various oral inflammatory disorders, PPOELs and OSCC.

\section{LncRNA biogenesis}

LncRNAs are a class of RNA molecules whose transcript length is $>200$ nucleotides (22). Different lncRNA classifications have been established based on different criteria. The first criteria was presented by Jarroux et al (23), and IncRNAs which are $>10 \mathrm{~kb}$ belong to the groups of very long intergenic RNAs and macro lncRNAs. Examples of macro lncRNAs include antisense of IGF2R non-protein coding RNA, KCNQ1 opposite strand/antisense transcript 1 and GNAS antisense RNA1, which act as cis-silencers in mouse genomic imprinting (24). The second criterion, location with respect to protein coding genes, is commonly used. In this classification, 5 types (sense, antisense, bidirectional, intronic and intergenic) of lncRNAs are included (23). An example of nature antisense transcripts, which is one type of antisense lncRNAs, is antisense non-coding RNA in the INK4 locus, which is encoded by the NK4b-ARF-INK4a locus on chromosome 9p21 (25). According to the classification based on association with other DNA regulatory elements and loci, lncRNAs are divided into pseudogenes, enhancer lncRNAs and promoter-associated lncRNAs and 3'-untranslated region-associated RNAs (23). Long intergenic non-coding (LINC)RNA-p21 is an enhancer RNA, which originates from a p53 binding site associated with regulation of cyclin-dependent kinase inhibitor 1A (26). The associated biochemical pathways or stability of lncRNAs serve as characteristics for their classification, as demonstrated by stable unannotated transcripts (27), Xrn1 sensitive unstable transcripts (XUTs) (such as 5'-long terminal repeat antisense TY1 RNA and XUT1678) (28), Nrd1-unterminated transcripts (29) and cryptic unstable transcripts (for example promoter upstream transcript) (30). Furthermore, several subgroups of lncRNAs with a precise subcellular localization have been defined. Long non-coding mitochondrial RNAs (ncmtRNAs) are cytoplasmic IncRNAs while GAA repeat-containing RNAs and chromatin-enriched RNAs (cheRNAs) locate in the nucleus (23). For example, antisense mitochondrial non-coding RNA-2 and hemin-induced chromatin-enriched RNA downstream of fetal hemoglobin are ncmtRNAs and cheRNAs, respectively $(31,32)$. Lastly, hypoxia-induced non-coding ultra-conserved transcripts (HINCUTs), stress-induced lncRNA (si-lncRNA), senescence-associated lncRNA (SAL), non-annotated stem transcript, prostate cancer-associated transcripts serve as subgroups of another attribute used for
lncRNA classification: Association with specific biological processes (23). Hypoxia-inducible factor (HIF) induces HINCUTs to elevate transcription of nearby genes, which are involved in cellular signaling pathways and processes, such as glucose metabolism (33). Oxidative stress causes rapid and transient dynamics of si-lncRNAs in the nucleus and the cytosol, leading to their accumulation at polysomes, which subsequently induces transcription (34). Antisense very long intergenic ncRNA (VAD), one type of SAL, modulates chromatin structure in cis and increases gene expression in trans at the INK4 locus, which encodes cell cycle inhibitors, that are important to senescence-associated cell proliferation arrest (35). The schematic diagram illustrating various classes of IncRNAs are presented in Fig. 2.

LncRNA can also be classified according to their function. LncRNAs exert or execute their functions in four main ways: Signal, decoy, guide, and scaffold. They have been shown to impact cell macromolecular (protein, RNA and DNA) stability (36). The regulatory mechanism of lncRNAs vary based on their locations within the cells. They participate in chromatin modification and transcription in the nucleus, while they interact with RNA-binding proteins or modulate mRNA translation in the cytoplasm $(37,38)$. There are a variety of mutual regulatory mechanisms for lncRNAs and miRNAs. LncRNAs can not only be mediated by miRNAs but also act as miRNA precursors. It is noteworthy that the ceRNA network is one of the common sites of posttranscriptional regulation (12). In the last 5 years, it has been demonstrated that $\operatorname{lncRNAs}$ are important in the regulation of a healthy immune system, which in turn is important for healthy oral tissue $(39,40,41)$. An increasing number of lncRNAs have been reported to regulate the differentiation and activation of immune cells. The differentiation of granulocytes is partly mediated by HOX antisense intergenic RNA myeloid 1 (HOTAIRM1), an antisense IncRNA within the HOXA gene locus. Hallmark myeloid maturation-associated genes such as HOXA1/A2 would be inhibited by silencing HOTAIRM1 (42). The potential importance of lncRNAs in the immune response, inflammation and even cancers is emerging (43-45).

\section{Role of IncRNAs in oral inflammatory disorders}

Pulpitis. Pulpitis is a state of inflammation of the dental pulp. Most cases are due to penetration of a carious lesion into the pulp chamber (46). Pulpitis is classified as either reversible or irreversible (47). Huang and Chen (48) conducted a microarray analysis to establish IncRNA profiles of inflamed $(n=7)$ and normal ( $n=5$ ) pulp tissues. A total of 752 lncRNAs (338 upregulated and 414 downregulated) were significantly expressed. A total of 460 significantly upregulated genes were enriched in biological processes, such as immune system processes, immune and defense response, the response to stress, and cell activation. The results indicated that most lncRNAs might play roles in the immune system and inflammatory responses of dental pulp. Lei et al (49), performed a comprehensive analysis of a lncRNA-miRNA-mRNA ceRNA network by integrating the IncRNA profile from Huang and Chen (48), the miRNA profile from Zhong et al (50) and the gene expression profile from Galicia et al (51). A ceRNA regulatory network was created, which was composed of the lncRNA 


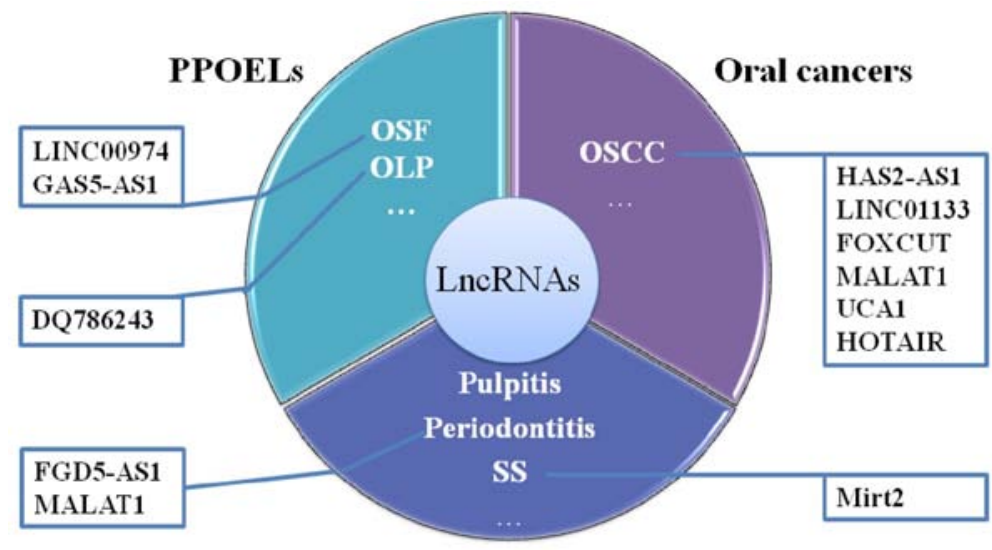

Oral inflammatory disorders

Figure 1. Oral diseases involving lncRNAs. PPOELs, potentially premalignant oral epithelial lesions; OLP, oral lichen planus; OSF, oral submucous fibrosis; OSCC, oral squamous cell carcinoma; SS, Sjögren's syndrome; lnc, long non-coding.

plasmacytoma variant translocation $1, \operatorname{miR}-455-5 \mathrm{p}$, and the mRNAs, suppressor of cytokine signaling 3 and Plexin $\mathrm{C} 1$. To the best of our knowledge, only one lncRNA microarray has been performed with a comprehensive analysis (49). There has been no mechanistic study focusing on specific lncRNAs in pulpitis. Thus, more research is required to explore the regulatory role of specific lncRNAs in pulpitis.

Periodontitis. Periodontitis is an inflammatory disease, which is primarily caused by bacterial infection (52). It can cause inflammation of the gingivae, loss of alveolar bone and loss of attachment (53). Tooth loss, which occurs in adults is largely due to periodontitis (54). In 2015, Zou et al (55) revealed for the first time that IncRNAs have critical roles in the pathogenesis of periodontitis. A total of 2 pairs of chronic periodontitis gingival samples and adjacent healthy samples were collected for IncRNA analysis and 8,925 DE IncRNAs were detected, of which 4,313 were upregulated and 4,612 were downregulated. Functional analysis of the nearby protein-coding genes revealed that different IncRNAs can regulate a common gene, and a single lncRNA can be regulated by different genes. Thus, lncRNAs might play crucial and dual roles in periodontitis.

Chen et al (4) found that IncRNA FGD5 antisense RNA1 (FGD5-AS1) was downregulated in the gingival samples from patients with chronic periodontal compared with that in healthy samples. FGD5-AS1 inhibited NF- $\mathrm{KB}$ signaling via the FGD5-AS1/miR-142-3p/suppressor of cytokine signaling 6 (SOCS6) ceRNA network and subsequently reduced the secretion of TNF- $\alpha$, IL-6, IL-1 $\beta$ and IL- 8 . Thus, the axis may provide a promising strategy for the treatment of periodontitis.

Several lncRNAs inhibit periodontitis; however, results from recent research have revealed that IncRNAs could promote the inflammatory process of periodontal-derived cells, including MALAT1 (7) and papillary thyroid carcinoma susceptibility candidate 3 (56). Li et al (7), explored the role of MALAT1 in inflammatory cytokine production in HGFs. The study indicated that MALAT1 bound to miR-20a, as a ceRNA and consequently led to increased mRNA levels of TLR4, which contributed to the activation of inflammation. Therefore, the effect and mechanism of MALAT1 in periodontal inflammation have been characterized.
SS. SS is a chronic systemic autoimmune disease characterized by reduced secretions of the salivary and lacrimal glands and associated neuroendocrine disturbances (57). The disturbances of neuroendocrine include release of hormones (i.e., glucocorticoids) via the hypothalamic-pituitary-adrenal axis stimulation, production of mediators within the sympathetic innervation of immune organs (i.e., thymus) and production of proinflammatory cytokines (i.e., IL-2 and TNF- $\alpha$ ) during the inflammatory response (58). The primary hallmark of SS is the infiltration of inflammatory mediators and cells, particularly $\mathrm{T}$ and $\mathrm{B}$ cells into the salivary and lacrimal glands (59). In addition, gland tissues have damaged acinar cells, fibrosis and increased adiposity with severe inflammatory lesions $(60,61)$. Therefore, exploration into the relevant molecular mechanisms underlying SS is required.

In 2019, Dolcino et al (62) performed a high-throughput gene and lncRNA expression profiling in peripheral blood mononuclear cell samples from 8 patients with primary SS (pSS) and 8 healthy subjects. Among the 199 lncRNAs that were identified, CTD-2020K17.1, LINC00511 and LINC00657 and their target genes were found to be involved in apoptosis, immune response, cell proliferation, and several proinflammatory pathways. Shi et al (63), compared the expression profiles of lncRNAs from labial salivary glands between patients with pSS and healthy individuals. The gene ontology and pathway analysis results found $28 \mathrm{DE}$ mRNAs associated with 8 DE lncRNAs were involved in chemokine signaling pathways, the NF- $\kappa \mathrm{B}$ signaling pathway, and the TNF signaling pathway. Taken together, the results suggest that samples from multiple tissues could be utilized for investigating the same oral autoimmune disease. A comparison of DE lncRNA sets from different sample types of the same disease could provide valuable clues to the discovery of novel therapeutic targets to treat oral autoimmune diseases.

Subsequently, Xin et al (5) demonstrated that lncRNA myocardial infarction associated transcript 2 (Mirt2) reduces apoptosis and inflammatory levels in interferon (IFN)- $\gamma$-induced inflammation in salivary gland epithelial cells. It is hypothesized that Mirt2 might block NF- $\mathrm{KB}$, and Janus kinase (JAK)/STAT3 signaling by increasing miR-377 expression levels. 
|

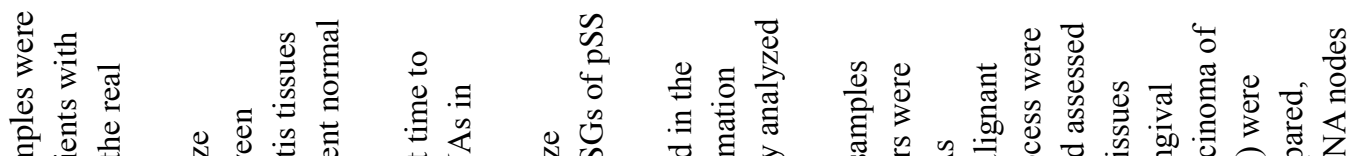

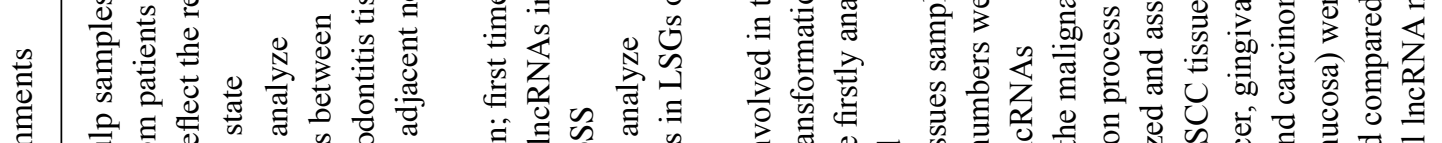

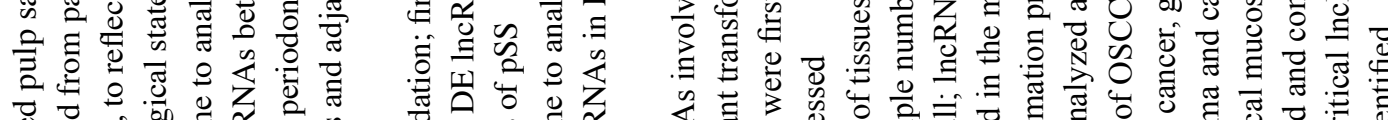

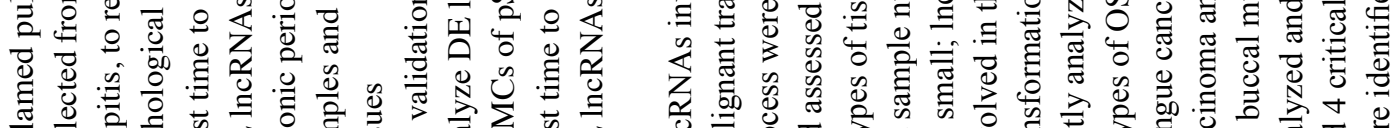

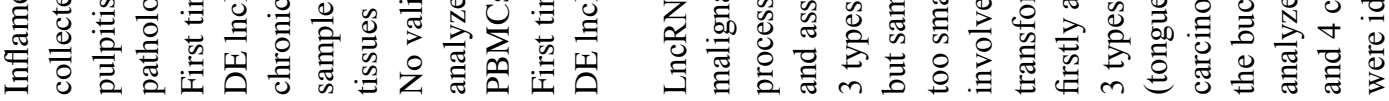

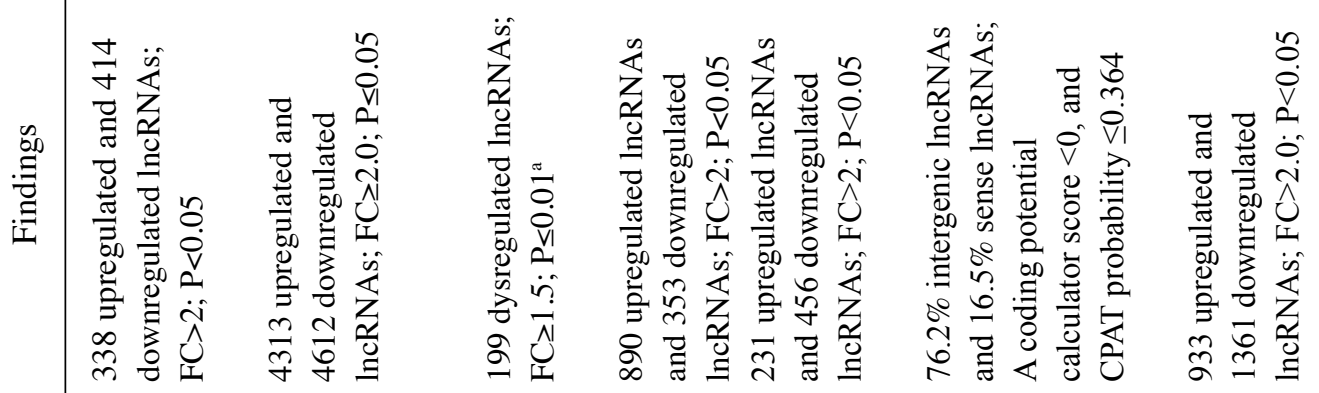

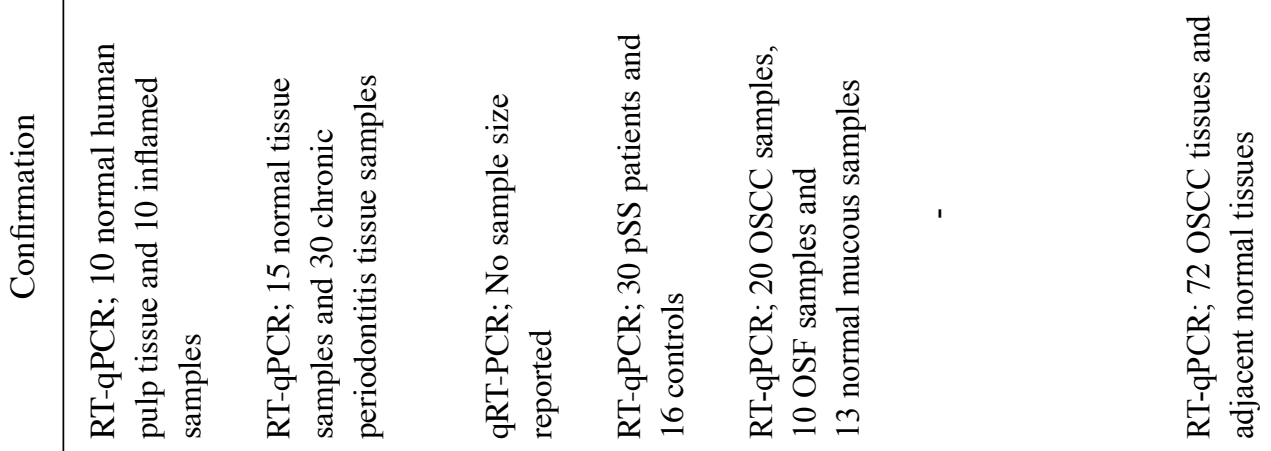

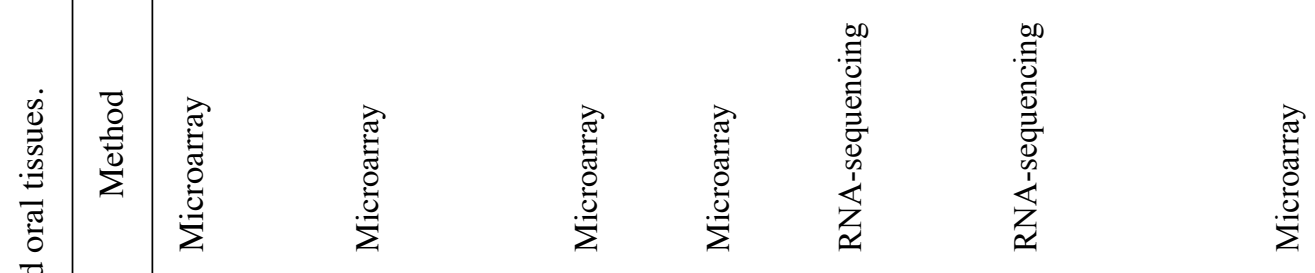

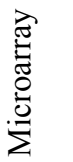

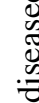


A

$>200 \mathrm{nt}$ AAAAAA Long non coding RNA

$>200 \mathrm{nt}$ AAAAAA $\begin{aligned} & \text { Large non coding RNA } \\ & \text { (OLE RNA, GOLLD }\end{aligned}$ RNA, HEARO RNA)

$>10000 \mathrm{nt}$ AAAAAA $\begin{aligned} & \text { Very long intergenic non } \\ & \text { coding RNA }\end{aligned}$

AAAAAA Macro IncRNA (Airn, Kcnqlotl, Nespas)

B

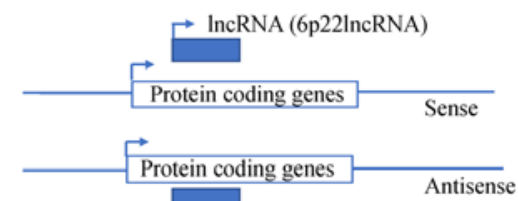
$\operatorname{lncRNA}($ ANRIL)

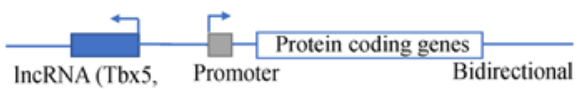
Tbx20, Nkx2-5)

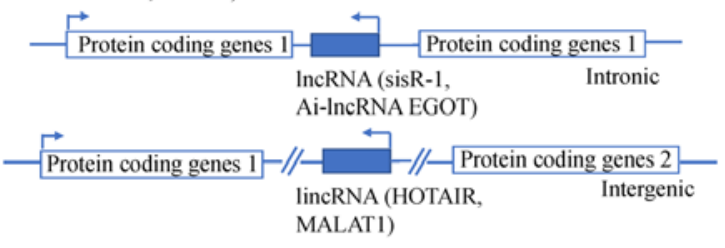

C
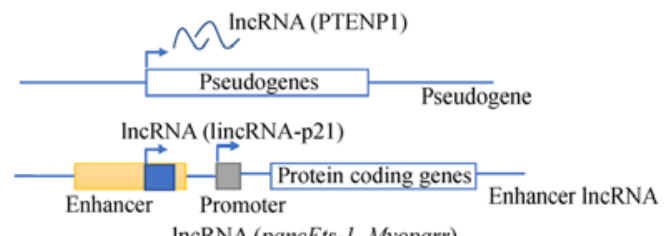

$\underset{\text { Promoter }}{\longrightarrow}$

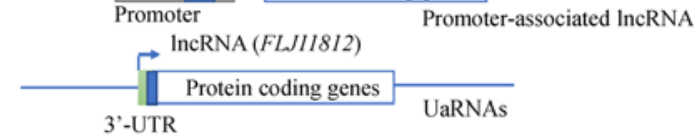

D

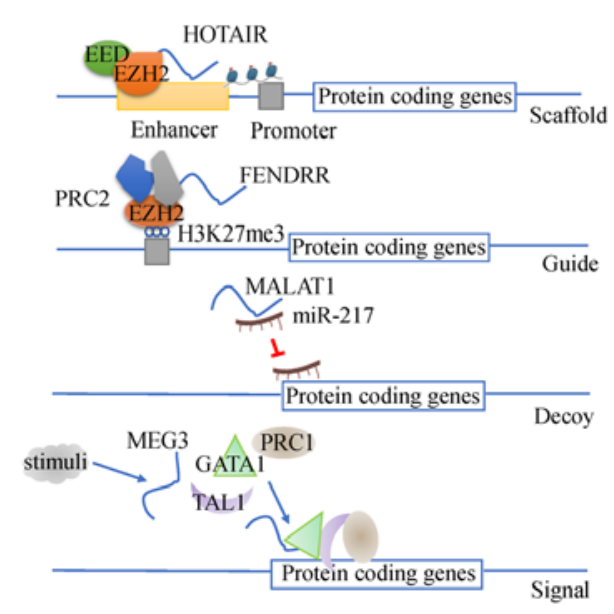

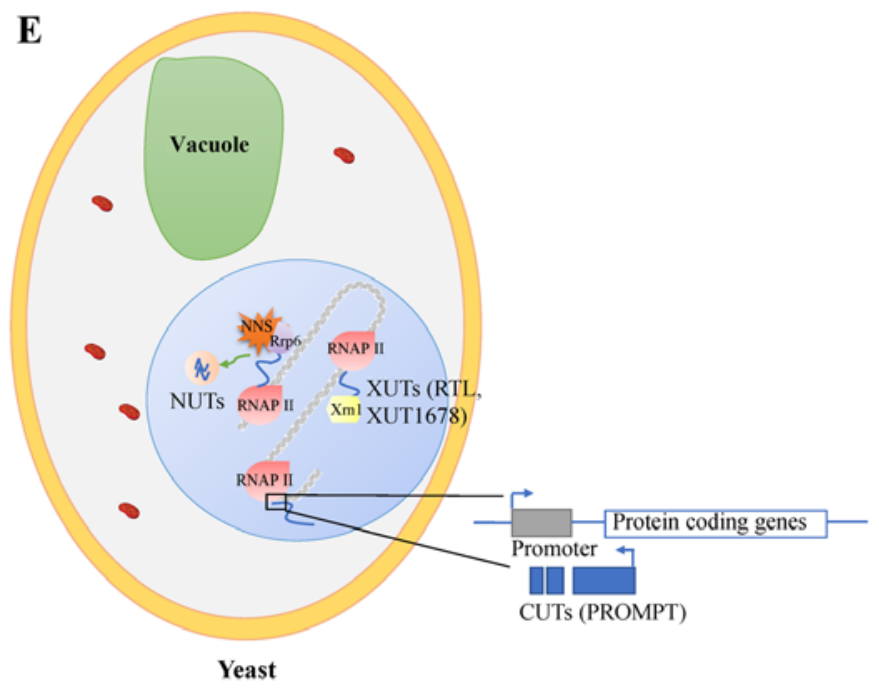

$\mathbf{F}$

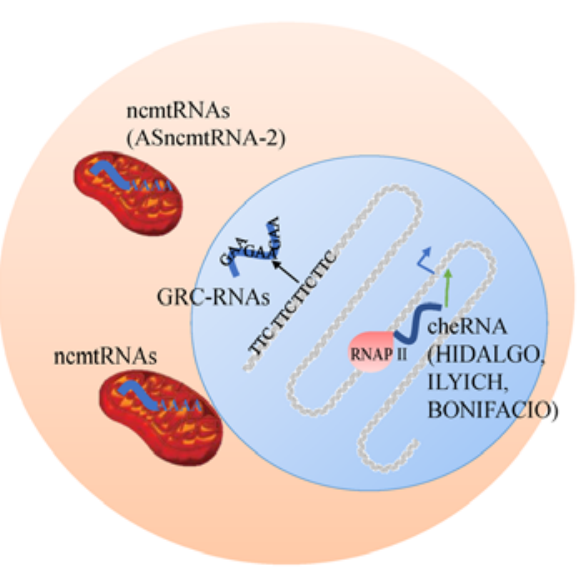

G

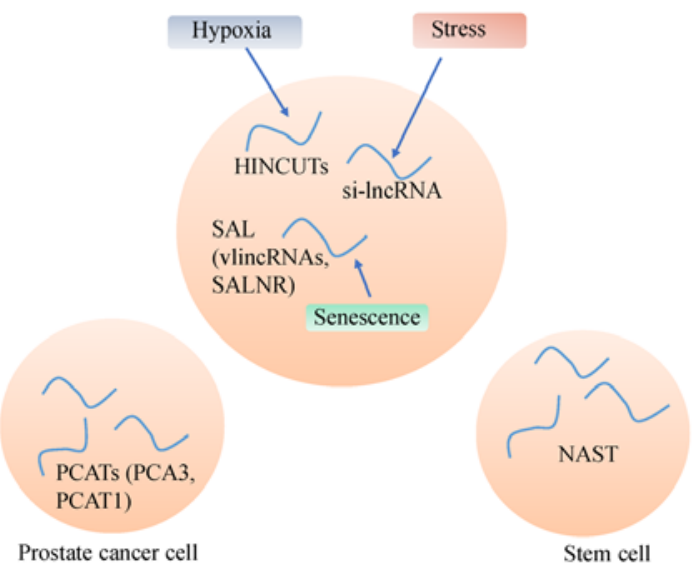

Figure 2. Schematic diagram of the various classes of lncRNAs. Classification according to lncRNAs (A) length, (B) location with respect to protein coding genes, (C) location with specific DNA regulatory elements and loci, (D) lncRNAs function, (E) biogenesis pathway and stability, (F) subcellular localization or origin. (G) association with specific biological processes. The green arrow indicates induction, and the red T indicates inhibition. HOTAIR, HOX transcript antisense RNA; MALAT1, metastasis associated lung adenocarcinoma transcript 1; UTR, untranslated region; uaRNAs, 3'-untranslated region-associated RNAs; EED, embryonic ectoderm development; EZH2, enhancer of zeste homolog 2; PRC2, polycomb repressive complex 2; RNAPII, RNA polymerase II; NUTs, Nrd1-unterminated transcripts; CUTs, cryptic unstable transcripts; XUTs, Xrn1-sensitive unannotated transcripts; PROMPT, promoter upstream transcript; ncmtRNAs, long noncoding mitochondrial RNAs; GRC-RNAs, GAA repeat-containing RNAs; cheRNA, chromatin-enriched RNA; si-lncRNA, stress-induced lncRNA; SAL, senescence-associated lncRNA; vlincRNAs, very long intergenic non-coding RNAs; SALNR, senescence-associated long non coding RNA; PCATs, prostate cancer-associated transcripts; PCA3, prostate cancer antigen 3; NAST, non-annotated stem transcript.

Research investigating lncRNAs typically involves the fields of medicine and biology; however, research regarding
lncRNAs in oral inflammatory disorders is still in the early stages. To date, the collection of clinical oral tissue samples 
and subsequent microarray or sequencing analysis has been the primary method of investigation in this field. In periodontitis, the majority of lncRNAs serve as ceRNAs $(4,6,7)$. There are a high number of research models investigating oral tissue-derived cells treated with related inflammatory stimuli (i.e., lipopolysaccharide and IFN- $\gamma$ ) (5,7). Periodontitis animal models and lncRNAs have been well-established (64-66), while animal models involving lncRNAs in other oral inflammatory disorders requires further investigation. Thus, additional research is required to determine the mechanism of lncRNAs in oral inflammatory disorders.

\section{Role of IncRNAs in PPOELs}

OSF. OSF is a chronic, occult oral mucosal disease associated with chewing betel nut, characterized by a juxta-epithelial inflammatory response followed by generalized submucosal fibrosis $(67,68)$. As a result, OSF typically leads to difficulty in opening the mouth and an increased malignant transformation rate $(69,70)$. Therefore, the identification of molecules associated with OSF pathological progression is urgent. In the course of OSF, endothelial dysfunction may be accompanied by the dysregulation of multiple lncRNAs (71). For example, lncRNA growth arrest specific 5 antisense 1 (GAS5-AS1) was inhibited, while lncRNA hypoxia-inducible factor $1-\alpha$ antisense RNA 1 (HIF1A-AS1) was upregulated during the development of OSF $(72,73)$. Research into lncRNAs has increased in the last 5 years; however, the function of numerous lncRNAs in OSF remains unclear. To date, only four articles have illustrated the relative issues (72-75).

The IncRNA sequencing conducted in 2019 by Zhou et al (75) included 13 normal mucous samples, 10 OSF samples, and 20 OSCC samples. A total of 5 DE candidate lncRNAs were found to participate in the inflammatory signaling pathway and contributed to inflammatory and fibroelastic pathogenetic changes by deregulating their cis-target and trans-target genes in OSF malignant development. Further functional analysis of these lncRNAs is required to provide conclusive evidence supporting an underlying regulatory mechanism during OSF.

Fang et al (74), determined that arecoline-induced myofibroblast trans-differentiation occurred via LINC00974-mediated activation of the transforming growth factor- $\beta$ (TGF- $\beta$ )/Smad signaling pathway. According to their study, collagen gel contractility and myofibroblast migration ability was increased in fibrotic buccal mucosal fibroblasts (fBMFs) overexpressing LINC00974. Increased expression of another lncRNAHIF1A-AS1 also positively modulates the TGF- $\beta /$ Smad signaling pathway, similar to LINC00974 (72). However, the lncRNA GAS5-AS1 presented contrary results in arecoline-treated BMFs and fBMFs (73).

$O L P$. OLP is a chronic inflammatory disease affecting the oral mucosa with characteristic relapses and remissions (76-78). Emerging evidence shows that OLP may be premalignant (79). Unstable molecular changes can induce the production of several inflammatory cytokines and subsequently contribute to the course of OLP $(77,80)$. For example, pathogen associated molecular patterns and adaptor molecules (i.e., myeloid differentiation factor 88) activation leads to nuclear translocation of $\mathrm{NF}-\kappa \mathrm{B}$ and augments the transcription of inflammatory genes (i.e., IL-6 and IL-8) (81). As with OSF, there have only been two studies on the role of lncRNAs in OLP to date.

Yang et al (82), examined DE genes and lncRNA targets in human papillomavirus-related OSCC $(n=1)$, normal $(n=1)$, and OLP $(n=1)$ samples. Of the identified lncRNAs, most $(697 ; 76.2 \%)$ were intergenic lncRNAs, followed by 151 sense lncRNAs (16.5\%). Keratinization and MHC class I antigen processing and presentation were significantly enriched by OSCC-associated DE genes and IncRNA targets, and the olfactory transduction pathway was enriched by OLP- and OSCC-related DE genes. To the best of our knowledge, this has been the only study investigating the lncRNA profile of OLP so far; however, the number of tissue samples was too small to guarantee the validity of these findings. In addition, there is evidence suggesting that lncRNA DQ786243 significantly enhances the expression levels of miR-146a by inducing Forkhead box P3 (Foxp3), which subsequently blocks NF- $\mathrm{B}$ signaling during OLP. Moreover, Foxp $3^{+}$regulatory $\mathrm{T}$ cells significantly suppressed the function of other $\mathrm{CD} 4^{+} \mathrm{T}$ cells, such as $\mathrm{CD} 4^{+} \mathrm{IL}-1^{+}$helper $\mathrm{T}$ cells and $\mathrm{CD} 4^{+} \mathrm{IL}-17^{+}$helper $\mathrm{T}$ cells, by inhibiting the mRNA expression levels of IFN- $\gamma$ and IL-17 (83).

LncRNA microarray analysis is considered a reasonable option for comparing and determining DE lncRNAs in normal, PPOEL and OSCC tissues, which are difficult to simultaneously acquire in one patient. Animal models which investigate both lncRNAs and PPOELs are expected to be explored extensively, and to primarily include fBMFs treated with related stimuli (i.e., arecoline). Mechanistically, the classical signaling pathways in PPOELs focus on the TGF- $\beta /$ Smad and $\mathrm{NF}-\kappa \mathrm{B}$ signaling pathways. Therefore, it is worth exploring more regulatory mechanisms [i.e., p38/MAPK and JAK/STAT3 signaling pathways] in subsequent studies on PPOELs.

\section{Role of IncRNAs in OSCC}

Oral cancers are cancers that exist in the oral cavity, such as the mucosal surfaces of the lips, floor of the mouth, tongue, buccal mucosa, lower and upper gingival surfaces, hard palate, and retromolar trigone (84). The histology of oral cancers varies widely; the majority of them are OSCCs (84). An increasing number of reports have revealed that IncRNAs play a broad role in the oncogenesis and progression of OSCC through transcriptional regulation, posttranscriptional modulation and epigenetic modifications (85). LncRNAs, functioning in oral cancer migration, epithelial-mesenchymal transition (EMT), metastasis, progression and invasion (86), could serve as biomarkers or therapeutic targets for OSCC diagnosis, prognosis and treatment (87).

With the development of whole transcriptome analyses, including serial analyses of gene expression, RNA sequencing and microarray data, several oral cancer-associated lncRNAs have been identified. In 2019, Qiu et al (88) screened 2,294 DE lncRNAs (933 upregulated and 1,361 downregulated) in OSCC tissues $(n=72)$ compared with paired adjacent normal tissues. A total of four IncRNA-mRNA coexpression networks were constructed, and low expression levels of the four lncRNA nodes contributed to poor median progression-free survival and overall survival. This study provided novel insights into the role of lncRNAs in OSCC. 


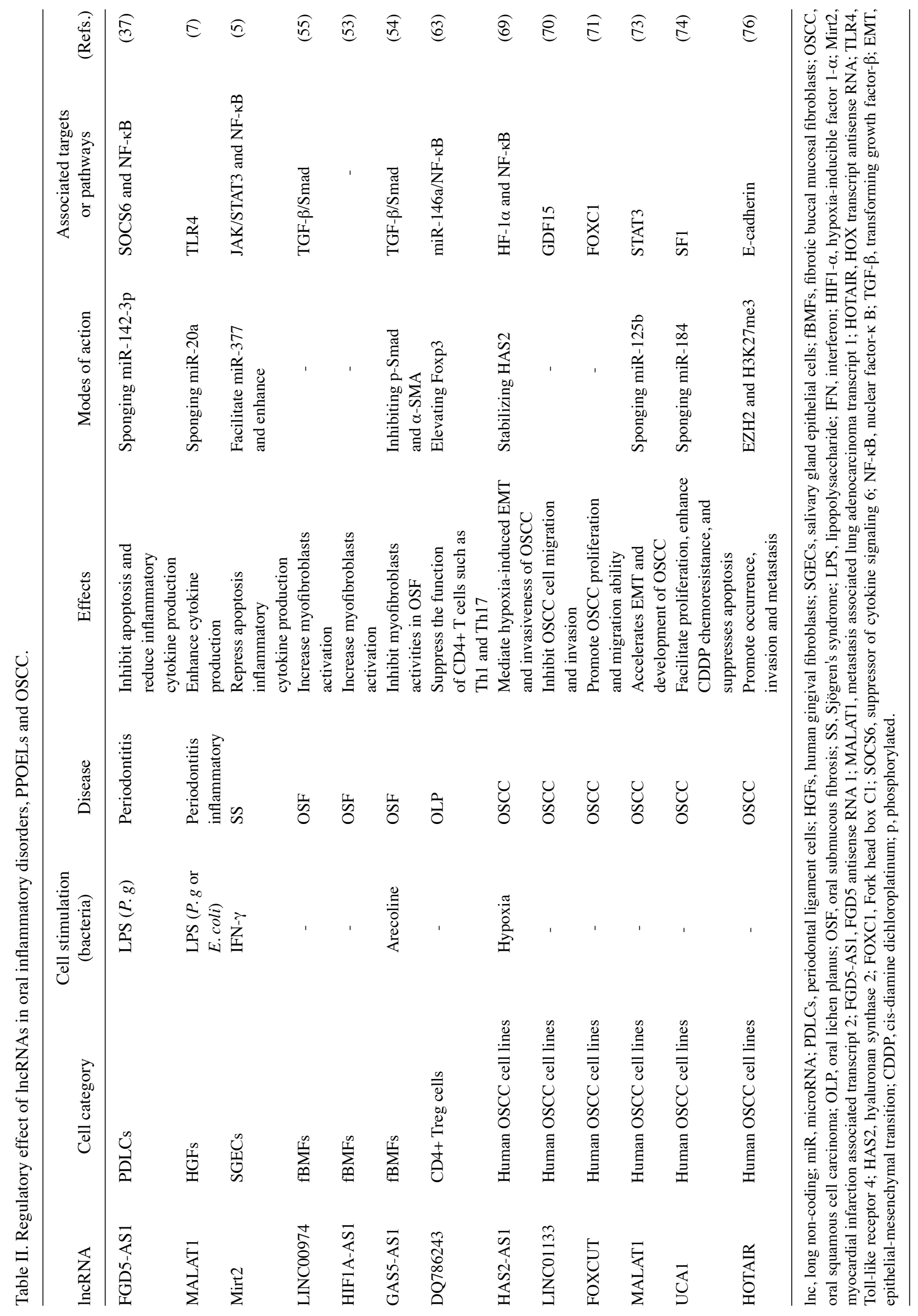




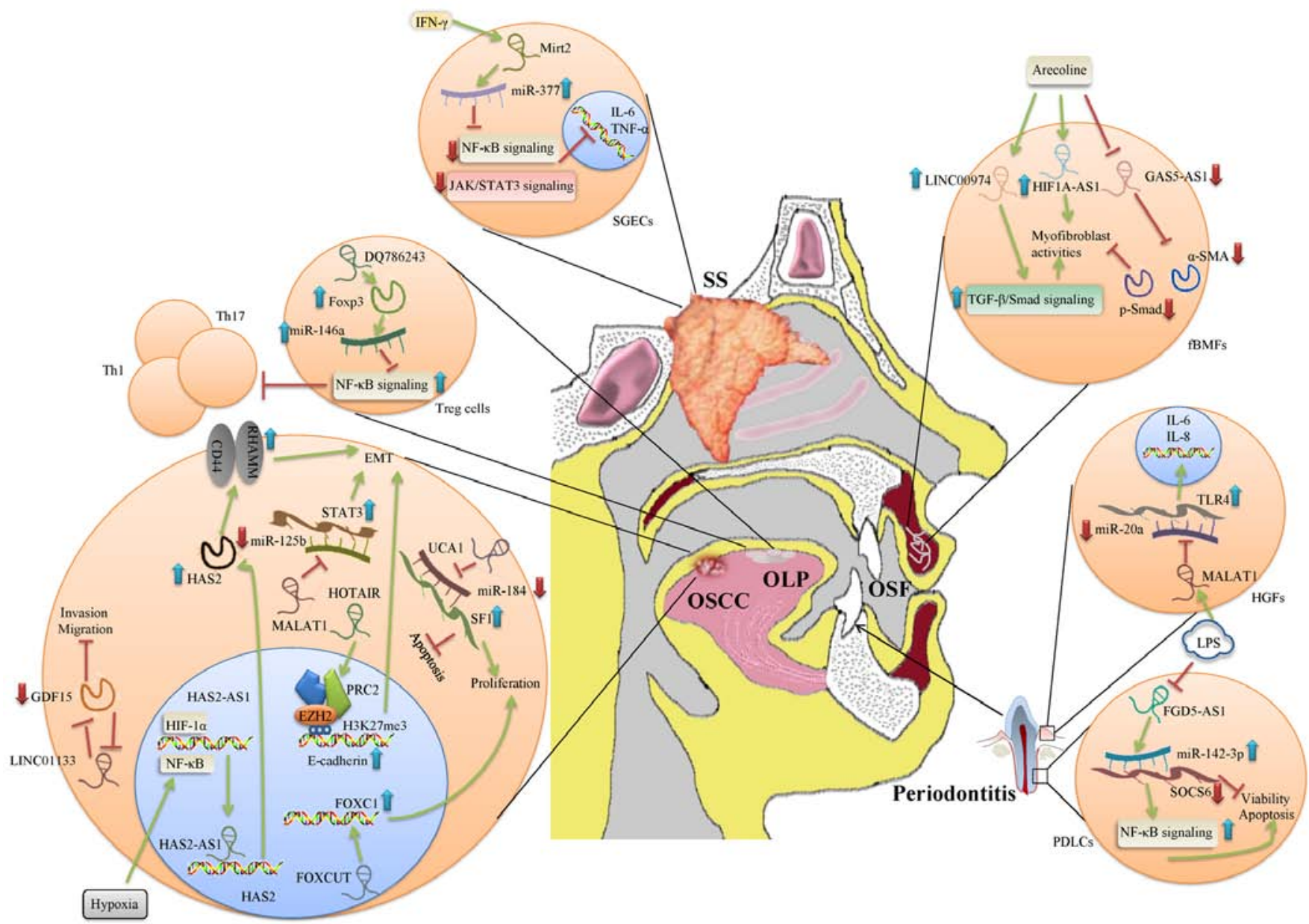

Figure 3. Schematic view of the biological processes involving lncRNAs in multiple oral diseases. The green arrow indicates induction, and the red T indicates inhibition. The blue arrow indicates an increase in expression levels of molecules or activation of pathways. The red arrow indicates a decrease in expression levels of molecules or inhibition of pathways. Lnc, long non-coding; HGFs, human gingival fibroblasts; SGECs, salivary gland epithelial cells; fBMFs, fibrotic buccal mucosal fibroblasts; SS, Sjögren's syndrome; OSCC, oral squamous cell carcinoma; OLP, oral lichen planus; OSF, oral submucous fibrosis; IFN, interferon; HIF1- $\alpha$, hypoxia-inducible factor 1- $\alpha$; Mirt2, lncRNA Myocardial infarction associated transcript 2; FGD5-AS1, FGD5 antisense RNA 1; MALAT1, IncRNA Metastasis Associated Lung Adenocarcinoma Transcript 1; HOTAIR, lncRNA HOX transcript antisense RNA; $\alpha$-SMA, myofibroblasts $\alpha$-smooth muscle actin; Foxp3, Forkhead box P3; HAS2, Hyaluronan Synthase 2; GDF15, growth and differentiation factor 15; FOXC1, Fork head box C1; SF1, splicing factor 1 ; TNF- $\alpha$, tumor necrosis factor- $\alpha$; RHAMM, receptor for hyaluronan-mediated motility; IL, interleukin; NF- $\kappa$ B, nuclear factor- $\kappa$ B; TGF- $\beta$, transforming growth factor- $\beta$; EMT, epithelial mesenchymal transition.

LncRNAs could transcriptionally regulate the progression of OSCC via interactions with proteins or interactions with RNA and DNA molecules (85). Zhu et al (89), verified that hypoxia induces the overexpression of hyaluronan synthase 2 antisense 1 (HAS2-AS1) in a HIF-1 $\alpha$ - and NF- $\kappa$ B-dependent manner. HAS2-AS1 mediates hypoxia-induced EMT and invasiveness of OSCC cells by binding and stabilizing the HAS2 gene. Additional research found that LINC01133 inhibited OSCC cell migration and invasion by inhibiting growth and differentiation factor 15 (GDF15) protein expression and formed a feedback regulatory loop with GDF15 (90). Kong et al (91), found that expression of 1ncRNA FOXC1 upstream transcript, which is the adjacent promoter upstream of the Fork head box $\mathrm{C} 1$ (FOXC1) gene, was positively correlated with FOXC1 mRNA expression and promoted OSCC proliferation and migration. Thus, a vast amount of research has elucidated transcriptional regulatory mechanisms to address the role of lncRNAs in OSCC.

Posttranscriptional regulation through pre-mRNA alternative splicing, mRNA decay acceleration, mRNA protection, or translational activation or repression is also one of the primary mechanisms of lncRNAs (92). Chang and Hu (93), demonstrated that MALAT1 could function as a ceRNA to mediate STAT3 expression by sponging miR-125b in OSCC. OSCC cell viability and growth were enhanced by increasing expression levels of MALAT1, and a role of MALAT1/miR-125b/STAT3 axis was confirmed in vivo using a nude mouse xenograft model with OSCC Tca8113 cells. Fang et al (94), found that lncRNA urothelial cancer associated 1 (UCA1) facilitated proliferation, enhanced cisplatin chemoresistance, and suppressed apoptosis in OSCC cells by suppressing miR-184 expression to increase the mRNA expression levels of splicing factor 1 . Thus, ceRNA appears to be a promising posttranscriptional regulatory mechanism in OSCC.

In addition, IncRNAs could affect the characteristics of OSCC through epigenetic modifications, including DNA methylation, chromatin modification and imprinting (95). LncRNA HOX transcript antisense RNA (HOTAIR) repressed the expression of E-cadherin by binding to enhancer of zeste homolog 2 , the enzymatic component of polycomb 
repressive complex $2(\mathrm{PRC} 2)$ and $\mathrm{H} 3 \mathrm{~K} 27 \mathrm{me} 3$ at the $\mathrm{E}$-cadherin promoter (96). HOTAIR silenced transcription factors by interacting with PRC2, lysine-specific histone demethylase-1 and RE-1 elements, leading to chromatin remodelling, thus trans-inhibiting the expression of the homeobox D cluster gene and promoting the occurrence, invasion and metastasis of tumors (96). Additional lncRNAs, participating in the progression of OSCC through epigenetic modifications, are expected to be detected, as there is an increasing number of the research being performed $(95,97)$.

Accumulating evidence has shown that lncRNAs modulate the metastasis, proliferation, invasiveness and migration of oral cancer, especially OSCC, in cellular physiological processes $(86,98,99)$. As aforementioned, lncRNAs interact with different cellular macromolecules, including chromatin, protein and RNA (36). According to the aforementioned studies, unstimulated OSCC cell lines are typically used for external models. Animal models are also well-established to provide more convincing evidence to confirm the role of lncRNAs in OSCC $(89,93,94)$. This suggests that lncRNAs have the potential to be prognostic and therapeutic markers, providing valid approaches for clinical treatment.

\section{Conclusion}

With the advent of genomic technologies, including microarrays and RNA sequencing, investigations of lncRNA genomic profiles have been widely performed in the last 5 years $(6,100,101)$. A large number of studies include microarray analyses of clinical tissue samples, which enhances the clinical value and significance of the findings $(48,55,88)$. The present review not only summarized the lncRNA profiles but also elucidated the potential underlying mechanisms of lncRNAs in oral diseases (Table II and Fig. 3). These mechanisms may be significant to the clinical diagnosis and therapy of oral diseases. Moreover, the present review focused on the identification and associations of oral inflammatory disorders, PPOELs and OSCC and discussed the functions of lncRNAs in the pathological process. By summarizing the studies involving the mechanisms of lncRNAs in oral diseases, ceRNA regulation was found to be the most common, while lncRNAs interacting with proteins is relatively rare. Thus, additional research is required to expand the early findings and characterize the mechanisms of DE lncRNAs. Overall, IncRNAs, the novel candidates in oral inflammatory disorders, PPOELs and oral cancer, should be investigated further, and their diagnostic and therapeutic functions may have significant value.

\section{Acknowledgements}

Not applicable.

\section{Funding}

This study was supported by the National Natural Science Foundation of China (grant nos. 81600882 and 81870755), a China Postdoctoral Science Foundation funded project (grant no. 2019M663009) and the President Foundation of Nanfang Hospital, Southern Medical University (grant no. 2019B002).

\section{Availability of data and materials}

Not applicable.

\section{Authors' contributions}

FF and BW contributed to the conception and design of the review. KZ contributed to the writing and drafting of the manuscript. FF and WQ contributed to the critical revision of the manuscript for important intellectual content. All the authors have given approval of the final version to be published and agree to be accountable for all aspects of the work.

\section{Ethics approval and consent to participate}

Not applicable.

\section{Patient consent for publication}

Not applicable.

\section{Competing interests}

The authors declare that they have no competing interests.

\section{References}

1. Brogden KA, Johnson GK, Vincent SD, Abbasi T and Vali S: Oral inflammation, a role for antimicrobial peptide modulation of cytokine and chemokine responses. Expert Rev Anti Infect Ther 11: 1097-1113, 2013.

2. Grivennikov SI, Greten FR and Karin M: Immunity, inflammation, and cancer. Cell 140: 883-899, 2010.

3. Kulkarni V, Uttamani JR, Naqvi AR and Nares S: microRNAs: Emerging players in oral cancers and inflammatory disorders. Tumour Biol 39: 1010428317698379, 2017.

4. Chen H, Lan Z, Li Q and Li Y: Abnormal expression of long noncoding RNA FGD5-AS1 affects the development of periodontitis through regulating miR-142-3p/SOCS6/NF-kB pathway. Artif Cells Nanomed Biotechnol 47: 2098-2106, 2019.

5. Xin M, Liang H, Wang H, Wen D, Wang L, Zhao L, Sun M and Wang J: Mirt2 functions in synergy with miR-377 to participate in inflammatory pathophysiology of sjogren's syndrome. Artif Cells Nanomed Biotechnol 47: 2473-2480, 2019.

6. Li S, Liu X, Li H, Pan H, Acharya A, Deng Y, Yu Y, Haak R, Schmidt J, Schmalz G and Ziebolz D: Integrated analysis of long noncoding RNA-associated competing endogenous RNA network in periodontitis. J Periodontal Res 53: 495-505, 2018

7. Li J, Wang M, Song L, Wang X, Lai W and Jiang S: LncRNA MALAT1 regulates inflammatory cytokine production in lipopolysaccharide-stimulated human gingival fibroblasts through sponging miR-20a and activating TLR4 pathway. J Periodontal Res 55: 182-190, 2020.

8. Lee PH, Chu PM, Hsieh PL, Yang HW, Chueh PJ, Huang YF, Liao YW and Yu CC: Glabridin inhibits the activation of myofibroblasts in human fibrotic buccal mucosal fibroblasts through TGF- $\beta$ /smad signaling. Environ Toxicol 33: 248-255, 2018.

9. Ganesh D, Sreenivasan P, Ohman J, Wallström M, Braz-Silva PH, Giglio D, Kjeller G and Hasséus B: Potentially malignant oral disorders and cancer transformation. Anticancer Res 38: 3223-3229, 2018.

10. Awadallah M, Idle M, Patel K and Kademani D: Management update of potentially premalignant oral epithelial lesions. Oral Surg Oral Med Oral Pathol Oral Radiol 125: 628-636, 2018.

11. Han X, Wei YB, Tian G, Tang Z, Gao JY and Xu XG: Screening of crucial long non-coding RNAs in oral epithelial dysplasia by serial analysis of gene expression. Genet Mol Res 14: $11729-11738,2015$.

12. Chen L, Zhou Y and Li H: LncRNA, miRNA and lncRNA-miRNA interaction in viral infection. Virus Res 257: 25-32, 2018. 
13. Chattopadhyay E, Singh R, Ray A, Roy R, Sarkar ND, Paul RR $\mathrm{Pal}$ M, Aich R and Roy B: Expression deregulation of mir31 and CXCL12 in two types of oral precancers and cancer: Importance in progression of precancer and cancer. Sci Rep 6: 32735, 2016.

14. Fiaschi $\mathrm{T}$ and Chiarugi P: Oxidative stress, tumor microenvironment, and metabolic reprogramming: A diabolic liaison. Int J Cell Biol 2012: 762825, 2012 .

15. Naylor MS, Stamp GW, Foulkes WD, Eccles D and Balkwill FR: Tumor necrosis factor and its receptors in human ovarian cancer. Potential role in disease progression. J Clin Invest 91: 2194-2206, 1993.

16. Yang G, Lu X and Yuan L: LncRNA: A link between RNA and cancer. Biochim Biophys Acta 1839: 1097-1109, 2014.

17. Yang ZH, Dang YQ and Ji G: Role of epigenetics in transformation of inflammation into colorectal cancer. World J Gastroenterol 25 2863-2877, 2019.

18. Katsanos KH, Roda G, Brygo A, Delaporte E and Colombel JF: Oral cancer and oral precancerous lesions in inflammatory bowel diseases: A systematic review. J Crohns Colitis 9: 1043-1052, 2015.

19. Jia H, Wang $X$ and Sun Z: Exploring the long noncoding RNAs-based biomarkers and pathogenesis of malignant transformation from dysplasia to oral squamous cell carcinoma by bioinformatics method. Eur J Cancer Prev 29: 174-181, 2020.

20. Camacho CV, Choudhari R and Gadad SS: Long noncoding RNAs and cancer, an overview. Steroids 133: 93-95, 2018.

21. Zhang J and Chu M: Targeting of IL-6-relevant long noncoding RNA profiles in inflammatory and tumorous disease. Inflammation 42: 1139-1146, 2019.

22. St LG, Wahlestedt $C$ and Kapranov P: The landscape of long noncoding RNA classification. Trends Genet 31: 239-251, 2015.

23. Jarroux J, Morillon A and Pinskaya M: History, discovery, and classification of IncRNAs. Adv Exp Med Biol 1008: 1-46, 2017.

24. Guenzl PM and Barlow DP: Macro lncRNAs: A new layer of cis-regulatory information in the mammalian genome. RNA Biol 9: 731-741, 2012

25. Beltrami C, Angelini TG and Emanueli C: Noncoding RNAs in diabetes vascular complications. J Mol Cell Cardiol 89: 42-50, 2015

26. Allen MA, Andrysik Z, Dengler VL, Mellert HS, Guarnieri A Freeman JA, Sullivan KD, Galbraith MD, Luo X, Kraus WL, et al: Global analysis of p53-regulated transcription identifies its direct targets and unexpected regulatory mechanisms. Elife 3: e2200 2014

27. Xu Z, Wei W, Gagneur J, Perocchi F, Clauder-Münster S, Camblong J, Guffanti E, Stutz F, Huber W and Steinmetz LM Bidirectional promoters generate pervasive transcription in yeast. Nature 457: 1033-1037, 2009.

28. Neil H, Malabat C, D'Aubenton-Carafa Y, Xu Z, Steinmetz LM and Jacquier A: Widespread bidirectional promoters are the major source of cryptic transcripts in yeast. Nature 457: 1038-1042, 2009.

29. Fox MJ, Gao H, Smith-Kinnaman WR, Liu Y and Mosley AL: The exosome component Rrp6 is required for RNA polymerase II termination at specific targets of the Nrd1-Nab3 pathway. PLoS Genet 11: e1004999, 2015.

30. Yu D, Ma X, Zuo Z, Wang $\mathrm{H}$ and Meng Y: Classification of transcription boundary-associated RNAs (TBARs) in animals and plants. Front Genet 9: 168, 2018.

31. Bianchessi V, Badi I, Bertolotti M, Nigro P, D'Alessandra Y, Capogrossi MC, Zanobini M, Pompilio G, Raucci A and Laur A: The mitochondrial lncRNA ASncmtRNA-2 is induced in aging and replicative senescence in endothelial cells. J Mol Cell Cardiol 81: 62-70, 2015

32. Werner MS, Sullivan MA, Shah RN, Nadadur RD, Grzybowski AT, Galat V, Moskowitz IP and Ruthenburg AJ: Chromatin-enriched lncRNAs can act as cell-type specific activators of proximal gene transcription. Nat Struct Mol Biol 24: 596-603, 2017.

33. Ferdin J, Nishida N, Wu X, Nicoloso MS, Shah MY, Devlin C, Ling H, Shimizu M, Kumar K, Cortez MA, et al: HINCUTs in cancer: Hypoxia-induced noncoding ultraconserved transcripts. Cell Death Differ 20: 1675-1687, 2013.

34. Giannakakis A,Zhang J, Jenjaroenpun P, Nama S, Zainolabidin N, Aau MY, Yarmishyn AA, Vaz C, Ivshina AV, Grinchuk OV, et al: Contrasting expression patterns of coding and noncoding parts of the human genome upon oxidative stress. Sci Rep 5: 9737, 2015.

35. Lazorthes S, Vallot C, Briois S, Aguirrebengoa M, Thuret JY, St Laurent G, Rougeulle C, Kapranov P, Mann C, Trouche D and Nicolas E: A vlincRNA participates in senescence maintenance by relieving $\mathrm{H} 2 \mathrm{AZ}$-mediated repression at the INK4 locus. Nat Commun 6: 5971, 2015 .
36. Dahariya S, Paddibhatla I, Kumar S, Raghuwanshi S, Pallepati A and Gutti RK: Long non-coding RNA: Classification, biogenesis and functions in blood cells. Mol Immunol 112: 82-92, 2019.

37. Chen LL and Carmichael GG: Decoding the function of nuclear long non-coding RNAs. Curr Opin Cell Biol 22: 357-364, 2010.

38. Fang F, Zhang K, Chen Z and Wu B: Noncoding RNAs: New insights into the odontogenic differentiation of dental tissue-derived mesenchymal stem cells. Stem Cell Res Ther 10: 297, 2019.

39. Geng F, Liu J, Guo Y, Li C, Wang H, Wang H, Zhao H and Pan Y: Persistent exposure to porphyromonas gingivalis promotes proliferative and invasion capabilities, and tumorigenic properties of human immortalized oral epithelial cells. Front Cell Infect Microbiol 7: 57, 2017.

40. Song Y, Pan Y and Liu J: Functional analysis of lncRNAs based on competitive endogenous RNA in tongue squamous cell carcinoma. PeerJ 7: e6991, 2019.

41. Ranzani V, Rossetti G, Panzeri I, Arrigoni A, Bonnal RJ, Curti S, Gruarin P, Provasi E, Sugliano E, Marconi M, et al: The long intergenic noncoding RNA landscape of human lymphocytes highlights the regulation of T cell differentiation by linc-MAF- 4 . Nat Immunol 16: 318-325, 2015.

42. Zhang X, Lian Z, Padden C, Gerstein MB, Rozowsky J, Snyder M, Gingeras TR, Kapranov P, Weissman SM and Newburger PE: A myelopoiesis-associated regulatory intergenic noncoding RNA transcript within the human HOXA cluster. Blood 113 : 2526-2534, 2009.

43. Elling R, Chan J and Fitzgerald KA: Emerging role of long noncoding RNAs as regulators of innate immune cell development and inflammatory gene expression. Eur J Immunol 46: 504-512, 2016.

44. Heward JA and Lindsay MA: Long non-coding RNAs in the regulation of the immune response. Trends Immunol 35: 408-419, 2014

45. Qu Q, Fang F, Wu B, Hu Y, Chen M, Deng Z, Ma D, Chen T, Hao Y and Ge Y: Potential role of long non-coding RNA in osteogenic differentiation of human periodontal ligament stem cells. J Periodontol 87: e127-e137, 2016.

46. Bjørndal L, Simon S, Tomson PL and Duncan HF: Management of deep caries and the exposed pulp. Int Endod J 52: 949-973, 2019.

47. Hui T, Wang C, Chen D, Zheng L, Huang D and Ye L: Epigenetic regulation in dental pulp inflammation. Oral Dis 23: 22-28, 2017.

48. Huang $X$ and Chen K: Differential expression of long noncoding RNAs in normal and inflamed human dental pulp. J Endod 44: 62-72, 2018

49. Lei $F$, Zhang $H$ and $X i e ~ X:$ Comprehensive analysis of an lncRNA-miRNA-mRNA competing endogenous RNA network in pulpitis. PeerJ 7: e7135, 2019.

50. Zhong S, Zhang S, Bair E, Nares S and Khan AA: Differential expression of microRNAs in normal and inflamed human pulps. J Endod 38: 746-752, 2012

51. Galicia JC, Henson BR, Parker JS and Khan AA: Gene expression profile of pulpitis. Genes Immun 17: 239-243, 2016.

52. Mombelli A: Microbial colonization of the periodontal pocket and its significance for periodontal therapy. Periodontol 200076 : 85-96, 2018.

53. Singhrao SK, Harding A, Poole S, Kesavalu L and Crean S: Porphyromonas gingivalis periodontal infection and its putative links with Alzheimer's disease. Mediators Inflamm 2015: 137357, 2015.

54. Michaud DS, Fu Z, Shi J and Chung M: Periodontal disease, tooth loss, and cancer risk. Epidemiol Rev 39: 49-58, 2017.

55. Zou Y, Li C, Shu F, Tian Z, Xu W, Xu H, Tian H, Shi R and Mao X: IncRNA expression signatures in periodontitis revealed by microarray: The potential role of lncRNAs in periodontitis pathogenesis. J Cell Biochem 116: 640-647, 2015.

56. Liu W, Zheng Y, Chen B, Ke T and Shi Z: LncRNA papillary thyroid carcinoma susceptibility candidate 3 (PTCSC3) regulates the proliferation of human periodontal ligament stem cells and toll-like receptor 4 (TLR4) expression to improve periodontitis. BMC Oral Health 19: 108, 2019.

57. Malathi N, Mythili S and Vasanthi HR: Salivary diagnostics: A brief review. ISRN Dent 2014: 158786, 2014

58. Tzioufas AG, Tsonis J and Moutsopoulos HM: Neuroendocrine dysfunction in Sjogren's syndrome. Neuroimmunomodulation 15: 37-45, 2008.

59. Zoukhri D: Effect of inflammation on lacrimal gland function Exp Eye Res 82: 885-898, 2006.

60. Gliozzi M, Greenwell-Wild T, Jin W, Moutsopoulos NM, Kapsogeorgou E, Moutsopoulos HM and Wahl SM: A link between interferon and augmented plasmin generation in exocrine gland damage in Sjögren's syndrome. J Autoimmun 40: 122-133, 2013. 
61. Reksten TR, Jonsson MV, Szyszko EA, Brun JG, Jonsson R and Brokstad KA: Cytokine and autoantibody profiling related to histopathological features in primary Sjogren's syndrome. Rheumatology (Oxford) 48: 1102-1106, 2009.

62. Dolcino M, Tinazzi E, Vitali C, Del PN, Puccetti A and Lunardi C: Long non-coding RNAs modulate Sjögren's syndrome associated gene expression and are involved in the pathogenesis of the disease. J Clin Med 8: 1349, 2019.

63. Shi H, Cao N, Pu Y, Xie L, Zheng L and Yu C: Long non-coding RNA expression profile in minor salivary gland of primary Sjögren's syndrome. Arthritis Res Ther 18: 109, 2016.

64. Jia B, Qiu X, Chen J, Sun X, Zheng X, Zhao J, Li Q and Wang Z: A feed-forward regulatory network lncPCAT1/miR-106a-5p/E2F5 regulates the osteogenic differentiation of periodontal ligament stem cells. J Cell Physiol 234: 19523-19538, 2019.

65. Huang Y, Han Y, Guo R, Liu H, Li X, Jia L, Zheng Y and Li W: Long non-coding RNA FER1L4 promotes osteogenic differentiation of human periodontal ligament stromal cells via miR-874-3p and vascular endothelial growth factor A. Stem Cell Res Ther 11: 5, 2020.

66. Wang L, Wu F, Song Y, Li X, Wu Q, Duan Y and Jin Z: Long noncoding RNA related to periodontitis interacts with miR-182 to upregulate osteogenic differentiation in periodontal mesenchymal stem cells of periodontitis patients. Cell Death Dis 7: e2327, 2016.

67. Canniff JP, Harvey W and Harris M: Oral submucous fibrosis: Its pathogenesis and management. Br Dent J 160: 429-434, 1986.

68. Tilakaratne WM, Klinikowski MF, Saku T, Peters TJ and Warnakulasuriya S: Oral submucous fibrosis: Review on aetiology and pathogenesis. Oral Oncol 42: 561-568, 2006.

69. Sharma M and Radhakrishnan R: Limited mouth opening in oral submucous fibrosis: Reasons, ramifications, and remedies. J Oral Pathol Med 46: 424-430, 2017.

70. Arakeri G, Patil SG, Aljabab AS, Lin KC, Merkx MAW, Gao S and Brennan PA: Oral submucous fibrosis: An update on pathophysiology of malignant transformation. J Oral Pathol Med 46 413-417, 2017.

71. Sharma M, Shetty SS and Radhakrishnan R: Oral submucous fibrosis as an overhealing wound: Implications in malignant transformation. Recent Pat Anticancer Drug Discov 13: 272-291, 2018.

72. Wang YK, Liu CM, Lin T, Fang CY, Yu CC and Yu CH: Inhibition of HIF1A-AS1 impedes the arecoline-induced migration activity of human oral mucosal fibroblasts. J Formos Med Assoc 119: 879-883, 2020

73. Lin CY, Liao YW, Hsieh PL, Lu MY, Peng CY, Chu PM, Yang HW, Huang YF, Yu CC and Yu CH: LncRNA GAS5-AS1 inhibits myofibroblasts activities in oral submucous fibrosis. J Formos Med Assoc 117: 727-733, 2018.

74. Fang CY, Yu CC, Liao YW, Hsieh PL, Lu MY, Lin KC, Wu CZ and Tsai LL: LncRNA LINC00974 activates TGF- $\beta /$ Smad signaling to promote oral fibrogenesis. J Oral Pathol Med 48: $151-158,2019$.

75. Zhou S, Zhu Y, He Z, Zhang D, Guo F, Jian X and Zhang C: Long non-coding RNA expression profile associated with malignant progression of oral submucous fibrosis. J Oncol 2019: 6835176, 2019.

76. Lodi G, Scully C, Carrozzo M, Griffiths M, Sugerman PB and Thongprasom K: Current controversies in oral lichen planus: Report of an international consensus meeting. Part 1. Viral infections and etiopathogenesis. Oral Surg Oral Med Oral Pathol Oral Radiol Endod 100: 40-51, 2005.

77. Eisen D, Carrozzo M, Bagan SJ and Thongprasom K: Number $\mathrm{V}$ oral lichen planus: Clinical features and management. Oral Dis 11: 338-349, 2005.

78. Scully C, Beyli M, Ferreiro MC, Ficarra G, Gill Y, Griffiths M, Holmstrup P, Mutlu S, Porter S and Wray D: Update on oral lichen planus: Etiopathogenesis and management. Crit Rev Oral Biol Med 9: 86-122, 1998.

79. Lončar-Brzak B, Klobučar M, Veliki-Dalic I, Sabol I, Pavelić SK, Krušlin B and Mravak-Stipetić M: Expression of small leucine-rich extracellular matrix proteoglycans biglycan and lumican reveals oral lichen planus malignant potential. Clin Oral Investig 22: 1071-1082, 2018.

80. Santoro A, Majorana A, Bardellini E, Festa S, Sapelli P and Facchetti F: NF-kappaB expression in oral and cutaneous lichen planus. J Pathol 201: 466-472, 2003.

81. Groeger S and Meyle J: Oral mucosal epithelial cells. Feonr Immunol 10: 208, 2019.

82. Yang Q, Xu B, Sun H, Wang X, Zhang J, Yu X and Ma X: A genome-wide association scan of biological processes involved in oral lichen planus and oral squamous cell carcinoma. Medicine (Baltimore) 96: e7012, 2017.
83. Wang J, Zhai X, Guo J, Li Y, Yang Y, Wang L, Yang L and Liu F: Long non-coding RNA DQ786243 modulates the induction and function of CD4(+) Treg cells through Foxp3-miR-146a-NF-kB axis: Implications for alleviating oral lichen planus. Int Immunopharmacol 75: 105761, 2019.

84. Huang SH and O'Sullivan B: Oral cancer: Current role of radiotherapy and chemotherapy. Med Oral Patol Oral Cir Bucal 18: e233-e240, 2013.

85. Gomes CC, de Sousa SF, Calin GA and Gomez RS: The emerging role of long noncoding RNAs in oral cancer. Oral Surg Oral Med Oral Pathol Oral Radiol 123: 235-241, 2017.

86. Luo X, Qiu Y, Jiang Y, Chen F, Jiang L, Zhou Y, Dan H, Zeng X, Lei YL and Chen Q: Long non-coding RNA implicated in the invasion and metastasis of head and neck cancer: Possible function and mechanisms. Mol Cancer 17: 14, 2018.

87. Zhang L, Meng X, Zhu XW, Yang DC, Chen R, Jiang Y and $\mathrm{Xu}$ T: Long non-coding RNAs in Oral squamous cell carcinoma: Biologic function, mechanisms and clinical implications. Mol Cancer 18: 102, 2019.

88. Qiu YL, Liu YH, Ban JD, Wang WJ, Han M, Kong P and Li BH: Pathway analysis of a genomewide association study on a long noncoding RNA expression profile in oral squamous cell carcinoma. Oncol Rep 41: 895-907, 2019.

89. Zhu G, Wang S, Chen J, Wang Z, Liang X, Wang X, Jiang J, Lang $J$ and Li L: Long noncoding RNA HAS2-AS1 mediates hypoxia-induced invasiveness of oral squamous cell carcinoma. Mol Carcinog 56: 2210-2222, 2017.

90. Kong J, Sun W, Zhu W, Liu C, Zhang H and Wang H: Long noncoding RNA LINC01133 inhibits oral squamous cell carcinoma metastasis through a feedback regulation loop with GDF15. J Surg Oncol 118: 1326-1334, 2018.

91. Kong XP, Yao J, Luo W, Feng FK, Ma JT, Ren YP, Wang DL and $\mathrm{Bu}$ RF: The expression and functional role of a FOXC1 related mRNA-lncRNA pair in oral squamous cell carcinoma. Mol Cell Biochem 394: 177-186, 2014.

92.Li Y, Zhang J, Pan J, Feng X, Duan P, Yin X, Xu Y, Wang X and Zou S: Insights into the roles of lncRNAs in skeletal and dental diseases. Cell Biosci 8: 8, 2018.

93. Chang SM and Hu WW: Long non-coding RNA MALAT1 promotes oral squamous cell carcinoma development via microRNA-125b/STAT3 axis. J Cell Physiol 233: 3384-3396, 2018.

94. Fang Z, Zhao J, Xie W, Sun Q, Wang H and Qiao B: LncRNA UCA1 promotes proliferation and cisplatin resistance of oral squamous cell carcinoma by sunppressing miR-184 expression. Cancer Med 6: 2897-2908, 2017.

95.Gonzalez-Ramirez I, Soto-Reyes E, Sanchez-Perez Y, Herrera LA and Garcia-Cuellar C: Histones and long non-coding RNAs: The new insights of epigenetic deregulation involved in oral cancer. Oral Oncol 50: 691-695, 2014.

96. Wu Y, Zhang L, Zhang L, Wang Y, Li H, Ren X, Wei F, Yu W, Liu T, Wang X, et al: Long non-coding RNA HOTAIR promotes tumor cell invasion and metastasis by recruiting EZH2 and repressing E-cadherin in oral squamous cell carcinoma. Int J Oncol 46: 2586-2594, 2015.

97. Yang CM, Wang TH, Chen HC, Li SC, Lee MC, Liou HH, Liu PF, Tseng YK, Shiue YL, Ger LP and Tsai KW: Aberrant DNA hypermethylation-silenced SOX21-AS1 gene expression and its clinical importance in oral cancer. Clin Epigenetics 8: 129, 2016.

98. Shao TR, Zheng ZN, Chen YC, Wu QQ, Huang GZ, Li F, Zeng WS and Lv XZ: LncRNA AC007271.3 promotes cell proliferation, invasion, migration and inhibits cell apoptosis of OSCC via the Wnt//-catenin signaling pathway. Life Sci 239: 117087, 2019.

99. Chen F, Qi S, Zhang X, Wu J, Yang X and Wang R: lncRNA PLAC2 activated by H3K27 acetylation promotes cell proliferation and invasion via the activation of Wnt/ $\beta$-catenin pathway in oral squamous cell carcinoma. Int J Oncol 54: 1183-1194, 2019.

100. Meseure D, Drak AK, Nicolas A, Bieche I and Morillon A: Long noncoding RNAs as new architects in cancer epigenetics, prognostic biomarkers, and potential therapeutic targets. Biomed Res Int 2015: 320214, 2015.

101. Ju H, Zhang L, Mao L, Wu Y, Liu S, Ruan M, Hu J and Ren G: A comprehensive genome-wide analysis of the long noncoding RNA expression profile in metastatic lymph nodes of oral mucosal melanoma. Gene 675: 44-53, 2018.

This work is licensed under a Creative Commons Attribution-NonCommercial-NoDerivatives 4.0 International (CC BY-NC-ND 4.0) License. 